Article

\title{
The European Struggle to Educate and Include Roma People: A Critique of Differences in Policy and Practice in Western and Eastern EU Countries
}

\author{
Christine O’Hanlon \\ School of Education \& Lifelong Learning, University of East Anglia, Norwich Research Park, Norwich, NR4 7TJ, UK; \\ E-Mail: c.o-hanlon@uea.ac.uk
}

Submitted: 3 June 2015 | Accepted: 16 November 2015 | Published: 15 February 2016

\begin{abstract}
Multiculturalism is an established feature of the UK and other European States since the establishment of the Treaty of Rome in 1959. Enlargement has brought EU membership from six (1952) to twenty eight members since its foundation, and allowed free migration across its borders. However, many countries, in spite of agreements to adhere to 'democratic' practices, deny minority citizens their full rights, particularly in education contexts. Some recent accession EU States have education systems that are less adaptive to expected policy responsibilities. It is a more unstable aspect of Eastern Europe because of the failure of many of these countries to reduce social and educational inequalities and to establish rights for minority groups, particularly the Roma. An educational focus is used as a platform to highlight issues re the segregation, and discrimination against, Roma children in Europe, typically through the use of special education, which is not suitable for them. Europe generally, both East and West has failed to fully integrate the Roma. Often, institutional blame is placed on Roma communities, rather than situate them socially and economically due to ingrained structural inequalities. Stereotyped categories are often used to 'label' them. Countries with high Roma populations, four in Western and five in Eastern Europe are evaluated and compared in relation to the education of Roma children.
\end{abstract}

\section{Keywords}

education; EU; inclusion; minority rights; Roma; structural inequality; Western and Eastern Europe

\section{Issue}

This article is part of the issue "Educating Nomadic People", edited by Caroline Dyer (University of Leeds, UK).

(C) 2016 by the author; licensee Cogitatio (Lisbon, Portugal). This article is licensed under a Creative Commons Attribution 4.0 International License (CC BY).

\section{Introduction}

Roma people form Europe's largest ethnic minority and have for centuries made up an intrinsic part of European society. But despite efforts at national, European and international level to improve the protection of their fundamental rights and advance their social inclusion, many Roma still face severe poverty, profound social exclusion, constraints to utilising their basic rights, and discrimination. These problems affect their access to quality education, which, in turn, undermines their employment and income prospects, housing conditions and health status, limiting their overall capacity to fully exploit their potential.

General development of any society depends upon high quality, inclusive and mainstream education. Edu- cation provides children and young adults with the necessary skills to enter employment and advance general social cohesion. Therefore the right to education is correctly embodied in international conventions and European Union (EU) documents. Education is also the only social right explicitly included in the European Convention on Human Rights (European Court of Human Rights [ECHR], 2011).

There are between 10 million and 12 million Roma living in the EU, at present comprising 28 countries. The most recent EU accession countries, situated in Eastern Europe include: Bulgaria, the Czech Republic, Hungary, Romania and Slovakia. The highest numbers of Roma populations, reaching more than $5 \%-10 \%$ of the population live in Bulgaria, the Czech Republic, Hungary, Romania, and Slovakia. These are the coun- 
tries that will be examined in this paper, together with the western EU countries of France, Italy, Portugal and Spain, because they are distinctive as western European countries with the highest number of Roma per capita population.

In recent years Romanian Roma have migrated throughout Europe, especially to Italy, Spain and France. In Spain and France they join Romani communities of several hundreds of thousands-over half a million in the case of Spain-although again not comprising anywhere near the \% age total of the Eastern European countries mentioned above. Roma make up around 0.64 per cent of the general population of France and 1.60 per cent of the population of Spain, 0.5 in Italy and $0.3 \%$ in Portugal (Chan \& Guild, 2008).

Roma who live in the European Union are EU citizens and have the same rights as all other citizens. A significant number of Roma live in extreme marginalisation in both rural and urban areas, and in very poor social-economic conditions. They are disproportionally affected by discrimination, violence, unemployment, poverty, bad housing and poor health standards.

The EU and Member States have a joint responsibility for Roma inclusion and use a broad range of funds in their areas of responsibility, namely the European Social Fund (ESF), European Regional Development Fund (ERDF) and the European Agricultural Fund for Rural Development (EAFRD) to support the implementation of national policies in these fields. The EU already co-finances projects for the Roma in sectors like education, employment, microfinance and equal opportunities, in particular, equality between men and women (Roma Education Fund, 2015).

When looking at general education for Roma in Europe, to all appearances it can be seen that education systems in Western Europe are advanced, highly developed and complex, but on closer examination although Eastern Europe displays some shocking and outdated practices for Roma, in the West there are still gross inequalities in Roma education. This article will examine specific Eastern European countries in comparison to selected Western European Union (EU) countries. The Eastern European countries are most deserving of examination, as they have only recently acceded to the EU. They also reflect different traditions in education, from values and attitudes, to policies and practices at local levels. Whereas Western European countries chosen have established educational traditions and practices over decades, since accession to the $\mathrm{EU}$ and adherence to its inclusive policy and practice in education (O'Hanlon, 2010).

There is a fundamental lack of accurate information on Roma in Eastern Europe. The official census data that does exist in these countries consistently underestimates the size of the Roma population and provides inadequate information about Roma participation in all spheres of life. This failure has far-reaching conse- quences: the lack of information renders policy and planning ineffective and makes it impossible to monitor changes. Inadequate data also perpetuates vast disparities in access to quality education. Inadequate information will continue to enable governments to evade responsibility for failing to create, fund, and implement effective programs for Roma inclusion. What is known for certain, however, is that only a tiny minority of Roma children ever complete school, and the education to which they have access is typically vastly inferior (Open Society Foundation, 2006).

Recently, two political initiatives (and policy frameworks) have highlighted the importance of education for Roma inclusion: the Decade of Roma Inclusion (DRI) 2005-2015, and the EU Framework for National Roma Integration Strategies up to 2020. The Decade of Roma Inclusion 2005-2015 is a political commitment at international level including nine governments in Eastern Europe, which aims to reduce socio-economic gaps that separate the Roma minority from other European citizens. Both policy directives emphasise the need for national governments to establish action plans and strategies for the educational inclusion of Roma children, alongside strong monitoring mechanisms up to 2020. Two essential areas for improvement are seen to be Roma educational access and ending educational segregation, with the emphasis on school completion and early school leaving. Neglect in these areas is mutually reinforcing and are contingent on each other (United Nations Development Programme [UNDP], World Bank, \& European Council, 2011).

\section{Special Schooling}

The Roma in Eastern Europe face greater challenges than any in Western Europe, although they are all faced with social and educational problems, often linked to poverty. Research evidence from Bulgaria, the Czech Republic, Romania, Hungary, and Slovakia affirms that Roma poverty rates far exceed those of the mainstream population. In effect all basic social indicators show inadequate levels in education, poor access to health care, inferior housing conditions, high unemployment and damaging discrimination. Roma frequently live in ghettos where there are poor employment opportunities and deteriorating socio-economic conditions linked to infrastructures and schools. In the Balkan countries Roma form the majority of refugees or internally displaced persons (IDPs), which puts them at risk regarding income, schooling and health (Bruggemann, 2012).

Yet, Roma communities in Western Europe often face similar levels of discrimination as their counterparts in Eastern Europe, according to recent reports by the EU and UN. Research indicates that the situation of the Roma is on average worse than their non-Roma neighbors when it comes to jobs, education, housing 
and health (European Union Agency for Fundamental Rights [FRA], 2014).

Many EU Member States, Roma children constitute a majority who are placed in special education schools and programmes, outside the mainstream educational system, although they have no apparent learning challenges or disabilities. One out of 10 Roma children have attended a special school or class that was mainly for Roma, even if only for a short period. Segregation in mainstream education is prevalent in the Czech Republic, Hungary, Slovakia and Romania, where 33\% to 58\% of Roma children in school attended a class where all, or many, children were Roma. Whereas, ethnically segregated school environments are uncommon in Italy, Portugal and Spain.

Of 23 countries in Eastern Europe included in a 2005 study by UNICEF, Slovakia had the highest enrolment rate of Roma children in basic special education programs in 2001, with enrolment rates in special education increasing between 1989 and 2001, to approximately 60\% (United Nations, 2006).

In Slovakia, Hungary, Bulgaria, Romania, the number of Roma attending segregated schools is much higher than the mainstream population. In Slovakia and Bulgaria, this number exceeds $30 \%$. The association between Roma communities and segregated school attendance is strongest in Slovakia where 34\% Roma attend with predominantly Roma students, compared to $5 \%$ for non-Roma.

The common practice of placing Roma children in 'special' schools or classes results in Roma overrepresentation in schooling that is ostensibly for children with intellectual disabilities or other special needs. This special schooling constitutes, per se, segregated education, irrespective of the ethnic composition of the students, because activities in these amenities are separate and different from those associated with mainstream education. They also offer reduced curricula and rarely enable their students to enter the general school system, higher education or subsequent employment.

A survey in 2011 shows that Roma children aged 7-15 years who attend special schools and classes exceeded $5 \%$ in Hungary, and $10 \%$ in the Czech Republic and Slovakia. Although, since then, there has been a decline from $25 \%$ to $17 \%$ in the Czech Republic (UNDP, 2015).

An extremely acute form of segregation occurs when Roma children make up the majority of the students in special schools. Many special schools in the Czech Republic, Slovakia, and Hungary, are ethnically segregated. In all countries the share of Roma attending ethnically segregated special schools is higher than the share of Roma attending ethnically segregated mainstream schools. In the Czech Republic and Slovakia, over $60 \%$ of all Roma who attend special schools are submitted to dual educational segregation because they attend special schools with a predominantly Roma majority.
The fall of communism and the recent shift to capitalist economies has not brought wealth or improved social conditions for the majority of Roma in Eastern Europe. It has been reported that, millions of Gypsies of Eastern Europe have emerged as great losers from the overthrow of Communism and the end of the rigid controls that it imposed on daily life.

Roma poverty has worsened dramatically in the transition from Communism. As a recent World Bank report notes: 'while Roma have historically been among the poorest people in Europe, the extent of the collapse of their living conditions in the former socialist countries is unprecedented (Ringold, Orenstein, \& Wilkens, 2003). It is reported by a witness that: in Communist days Roma had jobs and apartments and didn't have to pay for schoolbooks. They lived in better social conditions (Kamm, 1993).

However, what is the situation now in Eastern Europe and how do Roma children fare in education the $21^{\text {st }}$ century?

A review of five countries in Eastern Europe, which follows, demonstrates current issues in Roma education, with reference to post-communism, and tensions related to EU accession.

\section{Bulgaria}

Roma are the second largest minority in Bulgaria representing $4.7 \%$ (possibly unofficially $10 \%$ ) of the total population, which is the highest percentage of Roma in Europe. Historically Roma have occupied the lowest social strata in Bulgaria. Their level of education is low, but at present $10 \%$ of Roma are completely illiterate. After 1989 the agricultural and industrial production fell dramatically which led to the labour force being cut severely. Liberalisation has established high prices, high inflation, cuts in all social services, frozen salaries and high levels of unemployment leading to increased Roma poverty. Generally income and expenditure in Bulgaria is much below the EU poverty line (Bulgaria, 2015).

Although sociologists and economists explain depressed and lasting unemployment among the Roma as related to low education and qualifications, the Roma themselves believe it to be discrimination in education and the labour market. This assertion is confirmed when employment rates for Roma are compared to those with equal levels of experience and skill who are in work.

Since 1989 most of the benefits for Roma education were abolished, like free food, clothes and textbooks, which were available during the socialist era. Roma communities saw this change as discrimination against them. They refused to send their children to school, and this attitude of mistrust has continued to the present day. The mainstream population have not yet developed unbiased teaching materials, as there are still stereotyped accounts of Roma in history and literature textbooks. 
Roma children are often segregated from other children and face disadvantages in every aspect of their education from schooling to subsequent employment (European Union Monitoring and Advocacy Program [EUMAP], 2015). In the first two years of the DRI the country has scarcely begun the enormous task of Roma inclusion. Still many programmes and policies remain unfulfilled.

Only $15 \%$ of Roma Bulgarian children never enroll in schools and for those who do the dropout rate is 4 to 6 times higher than the national average. Roma children are put into segregated schools, or are in classes where the quality of education is inevitably lower, with an inadequate curriculum, poor resources and low teacher expectations.

It is disappointing that in spite of National Action Plans drawn up in the framework of the Decade of Roma Inclusion, when the problems of educational segregation are identified, no comprehensive approach has been established (Surdu, 2011). One example is the recommendation that more Roma children attend preschool ensuring their equal chances to education, as only $16 \%$ of Roma children attend pre-school in Bulgaria. However, the Bulgarian State is trying to address the improvement of Roma education by providing free textbooks for primary schools, some transportation and free meals. Since 2004 one obligatory year in preschool has been introduced as well as the employment of Roma teacher assistants, more extra-curricula classes in language and slow de-segregation of Roma children in schools (Bulgaria, 2015).

\section{Czech Republic}

Roma in the Czech Republic are a minority and according to the last census from 2011, the Roma nationality was reportedly claimed by the total of $13 \mathrm{~K}$ inhabitants. However, at the same census, over 40K inhabitants reported Romani language as their first language and, according to estimates by the European Roma Rights Centre, the size of the population is between $250 \mathrm{~K}$ and 300K (Radio CZ, 2015). Children in the Czech Republic are caught up in a cycle of poverty because of the failure of the education system to advance their opportunities. The majority of Roma are educated in 'practical' schools, where the curriculum is low-level and limited, and leaves them unqualified for all but the most basic jobs. In 2007 the European Court of Human Rights demanded that the Czech government end school segregation for Roma. However, the subsequent changes in practice are slow. Yet, steps have been taken to halt the exclusion of Roma children. There may be infringement proceedings against the government as a precursor to legal action at the European Court of Justice. The European Commission of Human Rights indicates that $30 \%$ of Roma children are still placed in special/practical schools compared to $25 \%$ of the mainstream population (Open Society Justice Initiative, 2012).

\section{Hungary}

Hungarian Roma are Hungarian citizens of Roma descent. According to the 2011 census, they compose $3.16 \%$ of the total population, which alone makes them the largest minority in the country, although various estimations have put the number of Romani people as high as $5-10 \%$ of the total population. For nearly 600 years, Hungary has struggled with the full inclusion of its Roma minority. Continued efforts at resolving issues stemming from failed attempts have only recently led to a serious consideration of education as a means of achieving this goal. Many non-governmental organizations, government agencies and grassroots movements have initiated projects aimed at increasing educational access for Hungary's Roma.

Hungary's lack of attention and lack of governmental support for the educational needs of impoverished Roma communities highlights a systemic failure to consider how significant an impact poverty can have on equal access to education. To make matters worse, the declining socio-economic status of many Roma communities has left them politically vulnerable and unable to advocate for the educational needs that would grant them equal access. Exacerbating the situation is the fact that the economic situation in Hungary has been worsening since the 1990s. Between 1990 and 2000 the number of Roma deemed to be poor has doubled (CEI Latvia, 2015).

Despite receiving government stipends for meals and other cost of living expenses, impoverished Roma families still struggle for access to educational facilities as early as pre-school. Inaccessibly distant schools are a financial burden for families living in Roma settlements due to the high costs associated with transportation, while those with access to nearby schools are usually excluded because of overcrowding. Also, transportation expenses and other access barriers disproportionately affect the number of impoverished Roma children able to attend pre-school at an early age. In most cases, children unable to attend pre-school by the age of five are automatically referred to special evaluation boards to test their school readiness and detect the presence of learning difficulties. Unfortunately, parents allow decisions about special schooling in segregated schooling to occur, because they are attracted by alleged benefits and are ignorant of protocol and professional procedures. This inevitably leads to a career in segregated education for their children.

Unfortunately, not all forms of segregation in the Hungarian educational system are as overt as its special schools and classes. It is also common for Roma children to be designated as private, or study-at-home students, should teachers and administrators deem 
their behaviour to be disruptive to other pupils. Consequently, a disproportionate number of Roma students do not obtain their education diplomas due to the prohibitions brought about by studying at home. Although some of these students may be classified as study-athome for reasons arising from a genuine concern for unaddressed behavioural issues, others may be victims of a discriminatory and corrupt financing system that facilitates educational segregation (Lopez, 2009).

In 2003 several amendments were added to the Act on Public Education that would allow financial incentives to be given to schools for the desegregation of their classes. However, it appears that closing down segregated schools brings about political liabilities that are costly. It is financially advantageous for schools to perpetuate the system of segregation. In spite of legal action against schools in towns and villages, the practice of special schooling for Roma children continues.

\section{Romania}

The Roma constitute one of Romania's largest minorities. According to the 2011 census, they number over $621 \mathrm{~K}$ or $3.3 \%$ of the total population, being the secondlargest ethnic minority in Romania after Hungarians (Romanian census, 2011). The Romani are Romania's most socially and economically disadvantaged minority, with high illiteracy levels. The unofficial number of Romani people in Romania is said to be as high as $850 \mathrm{~K}$.

Documenting Romania's Roma population remains difficult as many Roma do not declare their ethnicity in the census and do not have an identity card or birth certificate (Popescu, 2006). Yet in Romania social inclusion for Roma is a genuine progressive aim. It is defined in the official documentation of Europe and Romania as the provision of 'necessary opportunities and resources to fully participate in the economic, social and cultural life and to enjoy a standard of living and welfare considered to be normal in the society in which they live' (UNDP, 2015).

The National Agency for Roma created in 2004 has made an action plan to prioritise specific educational targets which include: extended school attendance for Roma children, developing capacity and motivation of Roma families reeducation, and increasing Roma employment opportunities. The evaluation of progress with these objectives is mixed. There has been some success at increasing Roma numbers at higher education but not all the free places reserved by the government especially for the Roma, have been taken up (European Roma Rights Centre [ERRC], 2004).

Since 2001, the Roma minority was the subject of several public policies developed by the European Commission and by specialised Romanian institutions at national level, in order to reduce its high risk of poverty and exclusion. However, according to a recent national survey of Roma, the Roma minority in Romania still remains the group with the highest probability of suffering discrimination (Nicolae, 2010). The last two decades have implemented government regulations to stimulate the social integration and to improve the situation of Roma re-education. The evaluation and research carried out shows the framework is beginning to be effective (UNDP, 2011).

The Strategy of the Government of Romania for the Inclusion of Roma who are Citizens of Romania for the Period 2012-2020 is the newest document related to Roma inclusion. The document is quoting the European Commission statement that 'Roma inclusion is a dual process which involves a change in the mentality of the majority and also in the mentality of the members of Roma community, a challenge that requires firm actions, developed in an active dialogue with Roma minority, both at national and EU level' (Friedman \& Surdu, 2009).

Some important gaps related to Roma minority education still persist, because they are contingent on social and economic factors internally and externally. Some of the Roma traditional values and family attitudes are slowing down the process of school inclusion and prohibiting the access to education for Roma children, examples are early marriage, child labour and uneducated parents.

Since 2001, the Roma minority was the subject of several public policies developed by the European Commission and by specialised Romanian institutions at national level, in order to reduce its high risk of poverty and exclusion. However, according to a national survey on the Roma condition, they still remain the group with the highest probability of suffering discrimination (Nicolae, 2010).

\section{Slovakia}

According to the last census from 2011, there were over 105K Roma in Slovakia, or $2.0 \%$ of the population. The Romani are the second-largest ethnic minority in Slovakia after Hungarians, and they live mostly in the eastern parts of the country. When comparing 23 countries in Central and Eastern Europe, Slovakia had the highest enrolment rate in special education in 2001 increasing year by year (UNICEF, 2006). Approximately $60 \%$ of children in special education in Slovakia in 2008-2009 are Roma, almost 15K. The disadvantages of special schooling are complex and include limited transfer to mainstream school; limited options for further education and educational results are greatly reduced. This leads to inadequate employment opportunities. Parents' acceptance of a special school placement is perplexing, as many are attracted to special schooling and unaware of the options available to them. The insidious use of psychological testing for Roma children immediately disadvantages them because of linguistic and cultural factors. Also, special 
schools for children with mild learning difficulties do not allow an enhanced support that would provide access to mainstream schools. This ultimately leads to a high number being unemployed or employed in low or un-skilled occupations.

Approximately $44 \%$ of Roma live in poverty, of which $15 \%$ live in extreme poverty. Implications of this low level of income emphasises the fact that Roma children are at risk of malnutrition in Eastern Europe, confirmed by findings that Roma children are underweight in comparison to the National average in Slovakia, three times as many children are underweight (United Nations, 2006).

Special schooling, which includes a majority of children from one ethnic minority, can be labeled as racial discrimination, because of the cumulative effects of poverty and lack of open access to mainstream schooling, healthcare and employment. Also, Roma settlements in isolated areas reduce their transport choices and they are unable to afford transport facilities and health insurance. Many Roma in these communities only speak Romani, which limits their communication with school and healthcare professionals (United Nations, 2006). How different is the situation for Roma children in Western Europe?

\section{France}

To begin with, no large scale quantitative research has been conducted in France, Italy, Spain or Portugal in recent years however, a survey conducted by FRA (2015) states that: France has possibly the harshest policy in Europe towards Roma immigrants. Most live in camps that are regularly demolished by police-and then rebuilt. Every year thousands are deported, but the overall number in the country remains the same (Astier, 2014).

11K Roma people were evicted across France last year-more than double the 2012 figure. Many of the evicted Roma end up being deported, more than any other immigrant group (ERRC 2016). Being a citizen of a European Union country offers little protection as EU law allows a member country to expel people who are deemed a burden on its social system. It is then speculative to imagine how Roma children are educated in such a climate of alienation and mistrust.

Local authorities systematically keep Roma children out of schools to avoid protests about demolition of camps or repatriation to their countries of origin. (Chazan, 2014).

More than half of Roma children living in France are not in school and local authorities are deliberately blocking their enrolment, and the ERRC has accused the authorities of failing to fulfill their legal obligations to provide schooling for Roma children (ERRC, 2016).

Further divisions have appeared between Roma who are citizens of a EU Member State and those who are not, such as Roma asylum seekers and migrants from outside of the EU. Those born in a certain Member State may now move freely to other Member States. This, in turn, has highlighted both the uniqueness and complexity of their status. Being a mobile minority, they are more likely to move between States, and they require recognition in their education systems. This is clearly problematic in countries such as France where, instead of recognising Roma as an ethnic minority with distinct minority rights, administrative categories, such as 'Travelling population' are created, which may ultimately fail to adequately address the social attributes of all Roma-sedentary and travelling alike (Farkas, 2007).

\section{Italy}

Until the 1990s, Roma living in Italy had been considered to be a recurring problem, a marginal group with no similarity to any other community because of their failure to assimilate and their endemic poverty. In terms of education, there have been attempts to increase Roma school attendance since the 1960s, but they have been largely unsuccessful. Even recently, less than half of Roma Gypsy children finish mandatory school in Italy (O'Nions, 2010). Data from the 1960s to 1990s show a slight increase in the last 5-6 years, particularly, in elementary school attendance. The latest city survey of Roma families living in Bologna-area camps, mostly arrived in the 90s, show high levels of attendance for elementary school, both among first and second generation Roma children. Yet, junior-high school and high school attendance is still low, around $25 \%$, and not increasing. As of today, nearly 15 years after the first large wave of migration from the Balkans, the second generation is starting to enter vocational training and higher education, not without difficulties (Fantone, 2009).

\section{Spain}

Roma children achieve the lowest rates of schooling and academic success in Spain and therefore there's a huge gap between the qualification and education of Spanish Roma and the majority population. There's also a huge level of absenteeism in Primary education and early school dropout, which are related to the socioeconomic and sociocultural situation of families. About $70 \%$ of Roma adults are illiterate, and are mainly women, which leads to social distance and inequality for generations of Spanish citizens who have been historically excluded and marginalised (DRI, 2015).

Roma schooling in Spain receives commendation for enrolling Roma children into primary school but performs terribly when it comes to higher education. Only $5 \%$ of Roma students complete upper-secondary education-a statistic that is even more shocking when 
you consider that Spain's intake is significantly behind less-developed European countries like the Czech Republic (30\%), Hungary (22\%), Romania (10\%), or Bulgaria (9\%). Roma students aren't in the classrooms, and their history isn't in textbooks: 500 years of Roma contributions to Spain fails to merit a single mention in school history books.

In contrast with Roma in Eastern Europe, Spanish Roma are not an officially recognized ethnic minority in the country, and Roma civil society is for the most part severely impoverished. After decades of state-funded service provisions through nongovernmental organizations, Roma are not flourishing in the mainstream society (Ovalle \& Mirga, 2014).

\section{Portugal}

Generally, Roma people are subjected to the same discrimination and prejudice as other European countries. The Roma are the major victim group in racist incidents, followed by black people from the Portuguesespeaking countries of Africa. It seems that the arrival of Roma/Gypsy groups in certain neighbourhoods has given rise to protests and even to demands that they leave. These protests reflect the tensions caused when different lifestyles co-exist side by side. The established, sedentary population often sees the arrival of travelling people in their neighbourhood as a threat. These fears are not necessarily or exclusively based on the difference in ethnic origin, but are also fuelled by prejudice creating a negative image of Roma/Gypsies (Fonseca, Caldeira, \& Esteves, 2002).

It has also been noted that Roma/Gypsy children have a high failure and dropout rate in Portugal. ECRI notes that the government is aware of this problem and has taken steps to encourage school attendance by Roma children, by ensuring, for example, that Roma/Gypsy culture is reflected in school curricula and textbooks. The main cause is attributed to the unsuitable curricula and textbooks that are not culturally relevant for Roma children. ECRI urges the government to continue its efforts and to step up action in this area (ECRI, 2013).

School segregation is also a widespread practice in Portugal, which has been noted since at least the late 1990s, with instances identified in different regions of the country, although most often in rural areas (in larger cities, social segregation tends to ensure school segregation). When documented, evidence has referred to classes in schools made up of Roma/Gypsy pupils only or, less commonly, schools attended only by these pupils.

In conclusion, the five Eastern European countries examined in this review demonstrate the long-lasting legacy of Communism in the majority, and the influence it still wields over the consciousness and practices of its populations.
Roma migration is a significant factor in the understanding of the situation in the Western European countries mentioned. Italy and Spain, traditionally known as countries of emigration became, by the end of the seventies, countries of immigration. During recent decades, since the fall of communism these countries have received increasing immigrant numbers, mostly from Eastern Europe. Romanians constitute the largest immigrant community in Italy, with approximately one million people. Romanians make up one third of total immigrants in Italy. In Spain, Romanians are also the most numerous immigrant populations amounting to almost 1 million. Bulgarians also emigrate towards these two Southern European countries, but prefer Spain to Italy. A number of these countries have suffered the consequences of recent upheaval and war e.g., Serbia and Croatia, and many Roma have been targeted in these conflicts. Since as early as the $12^{\text {th }}$ century tales of their persecution have flourished. Their reluctance to change and adapt to new and often threatening ways of life is seen to constrain their progress, at least according the prevailing hegemony in Europe. The economic pressure of neoliberalism and the development of a capitalist culture in Europe is one the Roma has not yet fully embraced because finding employment in this environment requires educational (professional or vocational) qualifications, or certification, by accepted sovereign State institutions. Often this leads to reluctance on the part of the Roma to become fully immersed in contemporary societal mores (O'Hanlon, 2014).

One thing that clearly emerges from this analysis is the fact that countries like France, Italy and Spain have one feature in common with Roma communities in Hungary, Romania and Slovakia, which is, that they are worse off than the mainstream citizens in each country. It would be expected that such migration to better off Western European countries would bring significant improvements to the Roma communities, yet, there are few differences in their lives (UNDP, 2014). Some clear regional patterns emerge from the results. Romania registered the highest scores for poverty-related reasons (costs of education), which also emerged among the top three categories in Bulgaria, Hungary and Slovakia. In western European countries, however, financial reasons are not as significant.

Another aspect that emerges is, that the Eastern European countries share many common issues and concerns in relation to the education of their Roma communities. Roma children are unnecessarily placed in segregated schools or classes where the quality of education received is invariably lower. There are also throughout:

- lower standards operating in the curricula of these schools and classes

- inappropriate assessment methods 
- inadequate resources in Roma schools

- teachers with low qualifications and therefore expectations are also low

- classroom materials reflecting prejudice

- text books and other sources which are not culturally or linguistically friendly for Roma children.

- few efforts are made to train Roma oriented teachers and assistants to support their language and culture

- statistics on Roma children, school attendance and their progress are rarely comprehensive or reliable

- school dropout rates are the highest of any ethnic minorities in any country

- social segregation is both caused and exacerbated by Roma communities settling in rural areas, leading to 'Roma schools' and segregated schooling

- there are not enough free pre-school places

In every way schools for Roma children are inferior to mainstream schools and many societies, both East and West, still oppose inclusive education for Roma children. Teacher professional development has not yet succeeded in eradicating older traditional ways of teaching, which are outdated, and a constraint to Roma children who need more culturally appropriate materials and eclectic teaching methods to learn.

The differences between Roma and non-Roma are statistically significant in all EU member States and show that Roma who are unable to read and write are declining for each successive age group in most EU Member States. This trend is particularly impressive in Portugal where the share of illiterate Roma has dropped from $60 \%$ among those aged 45 and older, to $10 \%$ for those aged 16 to 24 , and in Spain, where the rates decreased from $35 \%$ to $1 \%$.

The decline in illiteracy in the Czech Republic, Hungary, and Slovakia is associated with the expansion of education during communism after the Second World War. In these Eastern European countries, primary education became compulsory during the early years of state socialist regimes in the late 1940s and the early 1950s, during which time education was expanded. However, in Romania and Bulgaria it was less pronounced (FRA, 2015).

Exclusion from education takes different forms: from denial of school access to placement in 'special schools' or ethnically segregated classes. Ethnic segregation is influenced by factors ranging from residential characteristics to anti-Roma prejudice. In 2007, the European Court of Human Rights concluded in a landmark judgment that placing Roma children in special schools on the basis of their ethnic origin violated the governments' obligation to ensure children's access to educa- tion without discrimination, based on accumulated evidence from official Equality and Roma related organisations. It was found that on average only $12 \%$ of the Roma aged 18 to 24 had completed upper-secondary general or vocational education, yet, the situation is better for younger age groups, which shows that progress has been made (ECHR, 2011).

The problems faced by Roma are complex and therefore require an integrated approach to fight against low educational attainment, labour market barriers, segregation in education and in housing, and poor health outcomes, which, must all be addressed simultaneously. The EU has an important role to play in implementing such change, by improving legislation against discrimination, coordinating policy, setting common goals for inclusion and allocating funding.

The decrease in Roma illiteracy rates is less impressive in Eastern European (post-communist) countries, due to the lower initial level of illiteracy among the older generations compared to that in the long established EU Member States. At present, there is evidence of progress, however an EU Framework and national strategies are in place, and action plans are now being implemented. To continue making a tangible difference to Roma people's lives requires political will, efficient coordination of efforts and effective monitoring and evaluation tools by gathering and analysing data from the evidence on the ground, and testing novel approaches involving Roma communities at local level. Although, multiculturalism is an established feature EU States since the establishment of the Treaty of Rome in 1959, many countries, in spite of agreements to adhere to 'democratic' practices, deny minority citizens their full rights, particularly in education contexts. Some recent accession EU States have education systems that are less adaptive to expected policy responsibilities because of their past histories, and have failed to reduce social and educational inequalities and to establish rights for minority groups. An educational impetus is needed to further diminish segregation, and discrimination against Roma children in both Western and Eastern EU countries.

Europe generally has failed to fully integrate the Roma. Expulsion and repatriation of Roma migrants to their countries of origin is not a solution. Additional issues tend to ignore social and economic factors cause by ingrained systemic structural inequalities. The way forward lies not in simply including Roma children into long established schooling institutions and traditions, but rather through using creative, culturally relevant provision that is acceptable and sanctioned by Roma People themselves.

Fortunately, there are extensive numbers of new EU policies and, programmes and projects directly aimed at improving social and educational life for Roma. Yet, problems of research and evaluation longterm are linked to deficient data collection in Roma 
communities and schools. This leads to erroneous and unreliable assessments of the progress being made, resulting in sparse evidence for future analysis. These issues need to be addressed to generate a coherent and comprehensive agreed future EU agenda for Roma communities.

\section{Conflict of Interests}

The author declares no conflict of interests.

\section{References}

Astier, H. (2014, February13). France's unwanted Roma. $B B C$ News.

Bruggemann, C. (2012). Roma Education in comparative perspective. Analysis of the UNDP/World Bank/EC Regional Roma Survey 2011 (Roma Inclusion Working Papers). Bratislava: United Nations Development Programme. Bulgaria Education Ministry. (2015). Равен достьп на ромите до качествено образование: Преглед + Доклад за България [Equal access to quality education for Roma in Bulgaria]. Sofia. Education Ministry.

CEI Latvia. (2015) Information on Roma integration policy measures in Latvia. Latvia: Centre for Education Initiatives. Retrieved from ec.europa.eu/justice/ discrimination/files/roma_latvia_strategy_en.pdf

Chan, C., \& Guild, E. (2008). Top 5 facts sources: Study: Recent Migration of Roma in Europe. Strasbourg: Council of Europe Roma and Travellers Division.

Chazan, D. (2014, July 29). France excludes Roma children from schools. The Telegraph.

Decade of Roma Inclusion. (2015) Overview of education of Roma in Spain. Budapest: DRI.

ECRI. (2013). European Commission against racism and intolerance. ECRI Report on Portugal. Strasbourg: Council of Europe. Retrieved from www.coe.int/ecri

European Union Agency for Fundamental Rights. (2014). Education: The situation of Roma in 11 member states. Vienna: FRA.

European Union Agency for Fundamental Rights. (2015). Fundamental rights: Challenges and achievements in 2014: Annual Report. Vienna: FRA.

European Court of Human Rights. (2011). Protocol no. 14 Factsheet: The reform of the European Court of $\mathrm{Hu}$ man Rights. Strasbourg: European Court of Human Rights, Council of Europe.

European Roma Rights Centre. (2004) Romanian Government to establish new National Agency for Roma. Budapest: European Roma Rights Centre. Retrieved from http://www.errc.org/article/romanian-governm ent-to-establish-new-national-agency-for-roma/2102

European Roma Rights Centre. (2016). News and events. European Roma Rights Centre.

EUMAP. (2015) Monitoring minority protection in EU member states. New York: Open Society's EU Moni- toring and Advocacy Program.

Fantone, L. (2009). The exclusion of Romani children in Italian schools. Retrieved from www.academia.edu

Farkas, L. (2007). Segregation of Roma children in education: Addressing structural discrimination through the race equality. Brussels: EC.

Fonseca, M. L., Caldeira, M. J., \& Esteves, A. (2002). New forms of migration into the European South. International Journal of Population Geography, 8(2), 135152.

Friedman, E., \& Surdu, M. (.2009) School as ghetto: Systemic overrepresentation of Roma in special education in Slovakia. Vienna: FRA.

Kamm, H. (1993, November 17). End of communism worsens anti-Gypsy racism. New York Times.

Lopez, E. (2009). Romani education in Hungary: History, observances and experiences. Retrieved from www.fulbright.hu/book5/ericlopez.pdf

Nicolae, N. (2010, November 3). Romania is shirking its Roma responsibilities. The Guardian.

O'Hanlon C (2010). Whose education? The inclusion of gypsy/travellers: continuing culture and tradition through the right to choose educational opportunities to support their social and economic mobility. COMPARE, Journal of Comparative and International Education, 40(2), 239-255.

O'Hanlon, C. (2014). Roma/Traveller inclusion in Europe: Why informal education is winning. In R. Griffin (Ed.), Education and indigenous, nomadic and travelling communities (pp. 111-135). London: Bloomsbury Press.

O'Nions, H. (2010). Different and unequal: The educational segregation of Roma pupils in Europe. Intercultural Education, 21(1), 1-13.

Open Society Foundation. (2006). Monitoring education for Roma. New York: Open Society Foundation.

Open Society Justice Initiative. (2012). Failing another generation: The travesty of Roma education in the Czech Republic. New York. Open Society Justice Initiative.

Ovalle, O., \& Mirga, A. (2014, August 27). The myth of the Spanish model of Roma inclusion. Open Society Foundations.

Popescu, E. (2006). Roma are still victims of intolerance and discrimination Cronica Română [in Romanian]. Hyderabad, India: OMICS International.

Radio CZ. (2015, September 14). Decade of Roma inclusion fails to prevent segregation. Radio $C Z$.

Ringold, D., Orenstein, M., \& Wilkens, E. (2003). Roma in an expanding Europe: Breaking the poverty cycle. Retrieved from https://books.google.co.uk/books

Roma Education Fund. (2015). Closing the gap in educational outcomes between Roma and non-Roma. Budapest: Roma Education Fund.

Romanian census. (2011). Retrieved from www.edrc.ro

Surdu, M. (2011). From segregation to inclusion. Budapest: Roma Education Fund. Retrieved from www. 
romaeducationfund.hu/.../ref_uk_report_nov2011 UNICEF. (2006). At a glance: Slovakia. UNICEF. Retrieved from www.unicef.org/infobycountry/slovakia.html United Nations. (2006). At risk: Roma and the displaced in Southeast Europe. New York: United Nations.

United Nations Development Programme. (2011). Human development report 2011. Sustainability and equity: A better future for all. New York: UNDP.

United Nations Development Programme. (2014). Mi- gration of Roma and Non-Roma from Central and Eastern Europe. New York: UNDP.

United Nations Development Programme. (2015). United Nations Development Program-Romania 2011. Retrieved from http://www.cohre.org/news/pressreleases/cohre-housing-rights-awards-2006

United Nations Development Programme, World Bank, \& European Council. (2011) Regional Roma survey 2011. Budapest, Hungary: Center for Policy Studies.

\section{About the Author}

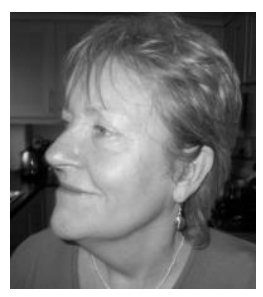

\section{Dr. Christine O'Hanlon}

Christine O'Hanlon has taught in a range of schools at all levels, then progressed to being an educator and researcher in higher education. She is focussed on 'marginalised' communities through her interest in educational segregation for pupils with special needs, Travellers and Roma. She supports change in communities through action research and pursues these aims both informally and formally through her role as Honorary Reader in Education at the University of East Anglia UK, and in community projects. 